\title{
A Methodology for Optimizing Tenon Geometry Dimensions of Mortise-and-Tenon Joint Wood Products
}

\author{
Wengang $\mathrm{Hu}^{1,2, *}$ and Bingrui Chen ${ }^{2}$ \\ 1 Co-Innovation Center of Efficient Processing and Utilization of Forest Resources, Nanjing Forestry University, \\ Nanjing 210037, China \\ 2 Department of Furniture Design, College of Furnishings and Industrial Design, Nanjing Forestry University, \\ Nanjing 210037, China; cbr@njfu.edu.cn \\ * Correspondence: wenganghu@njfu.edu.cn
}

Citation: $\mathrm{Hu}, \mathrm{W}$. ; Chen, B. A Methodology for Optimizing Tenon Geometry Dimensions of Mortise-and-Tenon Joint Wood Products. Forests 2021, 12, 478. https://doi.org/10.3390/f12040478

Academic Editor: Angela Lo Monaco

Received: 27 February 2021

Accepted: 12 April 2021

Published: 14 April 2021

Publisher's Note: MDPI stays neutral with regard to jurisdictional claims in published maps and institutional affiliations.

Copyright: (c) 2021 by the authors. Licensee MDPI, Basel, Switzerland. This article is an open access article distributed under the terms and conditions of the Creative Commons Attribution (CC BY) license (https:// creativecommons.org/licenses/by/ $4.0 /)$.

\begin{abstract}
For a long time, the geometry dimensions of tenons have been designed through empirical methods, which is not beneficial to designers and manufacturers and results in more time spent in construction and a greater amount of waste wood materials. In this study, an optimal methodology of combining finite element analysis (FEA) with response surface method (RSM) was proposed to investigate the effect of tenon geometric dimensions (length, width, and thickness) on withdrawal and bending load capacities of mortise-and-tenon (M-T) joints, with the aim of making the design of wood products more scientific. The following results were concluded: (1) the effect of tenon length on withdrawal load capacity was greater than tenon thickness, followed by tenon width; (2) the effect of tenon thickness on bending load capacity was greater than those of tenon width, followed by tenon length; (3) it was concluded that the tenon length should be designed to be greater than the tenon width and smaller than twice the tenon width, especially, when tenon thickness was relatively thin; (4) quadratic models can be used to predict the withdrawal and bending load capacities of M-T joints relating the length, width, and thickness of the tenon; (5) the proposed method was capable of being used to optimize the tenon sizes and get more knowledge of M-T joints visually. This study will contribute to reducing the costs of time and materials, and it will result in $\mathrm{M}-\mathrm{T}$ joints being designed more rationally.
\end{abstract}

Keywords: geometric dimensions; mortise-and-tenon joint; withdrawal; bending; FEA

\section{Introduction}

Mortise-and-tenon (M-T) joints have commonly been used in traditional wood frameworks, and are still used in wood structures and wood furniture. It is known that the mechanical properties of M-T joints influence the strength of the whole wood framework $[1,2]$. Withdrawal and bending loads are two common loading types that M-T joints are subjected to. It has been reported in previous studies that factors including wood species, joint type, glue type, loading type, and assembly time seriously influence the withdrawal and bending load capacities [3-9].

Previous studies have done some works on the withdrawal load capacities of M-T joints; Eckelman and his team did a series of studies on this topic, considering factors influencing the withdrawal load capacities [3]. In addition, the effect of wood species and tenon length on the withdrawal load capacity of M-T joint T-shaped samples has been studied [4], indicating that the glue line in the length of the tenon had a significant effect on the withdrawal load capacity of M-T joints. Additionally, Diler et al. [6] investigated the withdrawal load capacity of T-shaped M-T joints made from heat-treated pine, common ash, and irokowood, indicating that heat-treated wood reduced the withdrawal load capacity of the joint by 25\%. Furthermore, Barboutis and Melissides [10] reported that the withdrawal load capacity decreased with the increase of assembly delay, which might be the result of the rheology (relaxation and creep) of the wood. The methods used to increase the 
withdrawal load capacity of M-T joints, through using greenwood shrinkage as a clamping force, was proposed by Renbustu and Koizumi [11]. However, few studies have been found relating to the effect of tenon geometry dimensions on withdrawal load capacities.

In the case of bending load capacities or the bending moment of M-T joints, some experimental tests have been conducted to investigate the tenon geometric dimensions on the bending moment strength of $\mathrm{M}-\mathrm{T}$ joints. The following listed studies are representative of these: The effect of tenon geometric dimensions on the bending moment and stiffness were investigated by Wilczyński and Warmbier [12] through the use of the diagonal tension test method. The results suggested that the effect of tenon length on joint strength was greater than tenon width, followed by tenon thickness. The relationship between bending moment and rotation characteristics were investigated in relation to tenon geometry, grain orientation, length, and shoulder fit [13]. In addition, Oktaee et al. [14] reported that the effects of tenon length on the bending moment resistance of $\mathrm{M}-\mathrm{T}$ joints were more significant than tenon width when they were subjected to compression and tension. Kasal et al. [15] also studied the bending moment resistances of L-shaped M-T joints subjected to both compression and tension loadings, considering the effects of tenon sizes (width and length). Their results also showed that the tenon length had a greater effect on the bending moment resistance than the tenon width. Additionally, Erdil et al. [16] reported that the effect of tenon width on bending moment resistance was more significant than tenon length. Furthermore, the effects of tenon thickness on the bending elastic stiffness of samples were investigated, and the results suggested that the effect of tenon thickness on the bending elastic stiffness was more significant [17].

Tenon sizes (length, width, and thickness) are basic parameters of M-T joints, and they affect the strength of $\mathrm{M}-\mathrm{T}$ joints directly [18]. However, how to design the tenon geometry sizes rationally while considering the bending and withdrawal load capacities of $\mathrm{M}-\mathrm{T}$ joints together has rarely been studied because a large amount of work is required to make it feasible. Finite element analysis (FEA) has been confirmed as an effective method commonly used in wood engineering [19-23]. Previous studies also proved that FEA can be used to analyze M-T joints [24-28].

Therefore, in this study, a methodology has been proposed: The size effects of tenon geometry dimensions (length, width, and thickness) on the withdrawal and bending load resistances of M-T joints were investigated numerically by first using FEA. The relationship between withdrawal and bending load resistances relating to tenon geometric dimensions (length, width, and thickness) were then investigated using the response surface method (RSM), with the aim of resolving the issue of how to design tenon geometry rationally.

\section{Materials and Methods}

\subsection{Mechanical Properties of Wood}

The wood used to prepare the T-shaped specimens was beech (Fagus orientalis Lipsky) (Nanjing Wood Lumber, Nanjing, China). The density of the beech was $0.69 \mathrm{~g} / \mathrm{cm}^{3}$ and the moisture content (MC) was $10.8 \%$. The basic mechanical properties of beech wood have been tested in our previous study [29]. Table 1 shows the basic mechanical properties of beech wood, and these are basic parameters used in the finite element model, including elastic moduli, Poisson's ratios, shear moduli, yield strengths, and ultimate strengths. Polyvinyl acetate (PVA) was used to connect the mortise and tenon, and the bonding strengths of the M-T joints is also shown in Table 1 [30]. 
Table 1. Basic mechanical properties of beech and bonding strengths of Mortise-and-tenon (M-T) joints.

\begin{tabular}{|c|c|c|c|c|c|c|c|c|c|}
\hline \multirow{5}{*}{ Beech wood } & \multicolumn{3}{|c|}{ Moduli of Elasticity (MPa) } & \multicolumn{6}{|c|}{ Poisson's Ratio } \\
\hline & $\begin{array}{c}E_{\mathrm{L}} \\
12,205\end{array}$ & $\begin{array}{c}E_{\mathrm{R}} \\
1858\end{array}$ & $\begin{array}{c}E_{\mathrm{T}} \\
774\end{array}$ & $\begin{array}{c}v_{\mathrm{LR}} \\
0.502 \\
\end{array}$ & $\begin{array}{c}v_{\mathrm{LT}} \\
0.705\end{array}$ & $\begin{array}{c}v_{\mathrm{RT}} \\
0.526\end{array}$ & $\begin{array}{c}v_{\mathrm{TR}} \\
0.373 \\
\end{array}$ & $\begin{array}{c}v_{\mathrm{TL}} \\
0.038\end{array}$ & $\begin{array}{c}v_{\mathrm{RL}} \\
0.078\end{array}$ \\
\hline & \multicolumn{3}{|c|}{ Shear Modulus (MPa) } & \multicolumn{3}{|c|}{ Yield Strength (MPa) } & \multicolumn{3}{|c|}{ Ultimate Strength (MPa) } \\
\hline & $G_{L R}$ & $G_{\mathrm{LT}}$ & $G_{\mathrm{RT}}$ & $\mathrm{L}$ & $\mathrm{R}$ & $\mathrm{T}$ & $\mathrm{L}$ & $\mathrm{R}$ & $\mathrm{T}$ \\
\hline & 899 & 595 & 195 & 53.62 & 12 & 6.23 & 59.20 & 48.88 & 23.82 \\
\hline \multirow{2}{*}{ M-T joint } & \multicolumn{3}{|c|}{ Shear strength $G_{I}(\mathrm{MPa})$} & \multicolumn{3}{|c|}{ Shear strength $G_{I I}(\mathrm{MPa})$} & \multicolumn{3}{|c|}{ Normal strength (MPa) } \\
\hline & \multicolumn{3}{|c|}{3.49} & \multicolumn{3}{|c|}{2.45} & \multicolumn{3}{|c|}{1.23} \\
\hline
\end{tabular}

$E$ refers to elastic modulus (MPa); $v$ infers Poisson's ratio; $G$ is shear modulus (MPa); L, $\mathrm{R}$, and T are longitudinal, radial, and tangential grain orientations of beech, respectively; shear strength $G_{I}$ refers to the shear strength parallel to the direction of the tenon withdrawal direction; shear strength $G_{I I}$ is the shear strength perpendicular to the withdrawal direction; and normal strength is the internal bonding strength of the glued M-T joint in the flat contact surface.

\subsection{Configurations of Specimen}

Figure 1 shows the configurations of the T-shaped specimen and the M-T joint evaluated in this work. The dimensions of the post leg are $200 \mathrm{~mm} \times 40 \mathrm{~mm} \times 40 \mathrm{~mm}$ (length $\times$ width $\times$ thickness). The stretcher measured $160 \mathrm{~mm}$ long $\times 30 \mathrm{~mm}$ wide $\times 30 \mathrm{~mm}$ thick (length $\times$ width $\times$ thickness). Meanwhile, the dimensions of the tenon geometric dimensions were the variables evaluated in this study, i.e., tenon length (l): $20 \mathrm{~mm}, 30 \mathrm{~mm}$, and $40 \mathrm{~mm}$; tenon width $(w): 15 \mathrm{~mm}, 20 \mathrm{~mm}$, and $25 \mathrm{~mm}$; and tenon thicknesses $(t): 7.5 \mathrm{~mm}$, $10 \mathrm{~m}$, and $15 \mathrm{~mm}$. According to common wood M-T joint techniques, the 0.2 interference fit was applied between tenon width and mortise height, and the relationship between tenon thickness and mortise width was a $0.2 \mathrm{~mm}$ clearance fit.

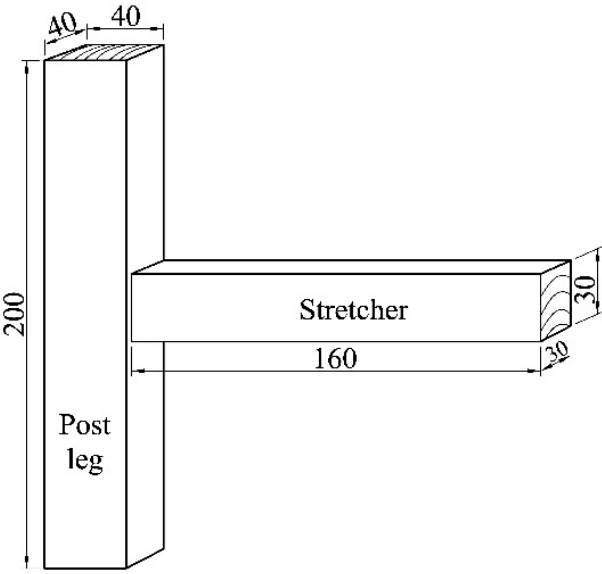

(a)

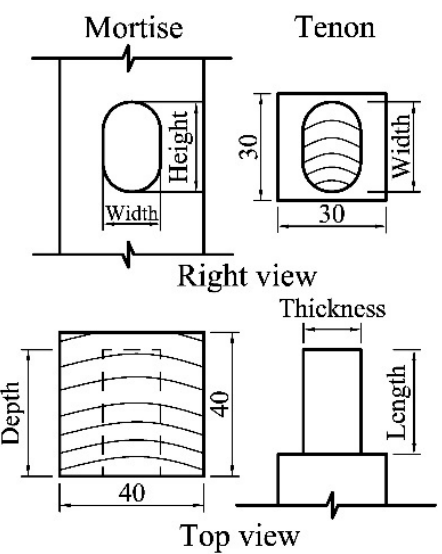

(b)

Figure 1. Dimensions of specimen: (a) T-shaped sample; (b) mortise-and-tenon joint.

\subsection{Finite Element Model}

Figure 2 shows the finite element models of the samples evaluated in this work subjected to withdrawal and bending load using ABAQUS 6.14-1 (Dassult, Providence, RI, USA) considering orthotropic properties, large deformation, and damage to the wood. The mechanical properties used in the models are shown in Table 1. In this study, Ductile Damage law was adopted as a stress criterion in the finite element model, and the parameters inputted were fracture strain of 0.00833 , stress triaxiality of 0.33 , strain rate of 0.01 , and displacement at failure of $0.6452 \mathrm{~mm}$. Local coordinates were used to define the grain orientations of the leg and the stretcher, i.e., the directions of $\mathrm{x}, \mathrm{y}$, and $\mathrm{z}$ corresponded to the longitudinal, radial, and tangential grain orientations, respectively. The oval M-T joint model was regarded as a semi-rigid joint. Surface-to-surface contact was applied as the interaction method between mortise and tenon. For the curve contact surfaces of 
the M-T joint, a $0.2 \mathrm{~mm}$ interference fit was exposed to simulate assembly force, and the Penalty Contact Property was applied with a friction coefficient of 0.54 [31] to simulate the friction behavior between the mortise and the tenon. For the flat contact surfaces of the $\mathrm{M}-\mathrm{T}$ joint, Maximum Stress law was used as a criterion to simulate the bonding behavior of the glue line between the M-T joint, and the parameters needed in ABAQUS were the bonding strengths of the glue joint shown in Table 1. A displacement load was applied to the reference loading point at the end of the stretcher to get the withdrawal load capacity $\left(F_{\mathrm{w}}\right)$ shown in Figure 2a, and a displacement load was imposed on the loading head to obtain the bending load $\left(F_{\mathrm{b}}\right)$ shown in Figure $2 \mathrm{~b}$. The mesh of the model is also shown in Figure 2, and the seed sizes of all elements were approximately $5 \mathrm{~mm}$. In the case of contact parts, the seed sizes of the elements were about $2 \mathrm{~mm}$. The C3D8 element was assigned to the T-shaped sample.

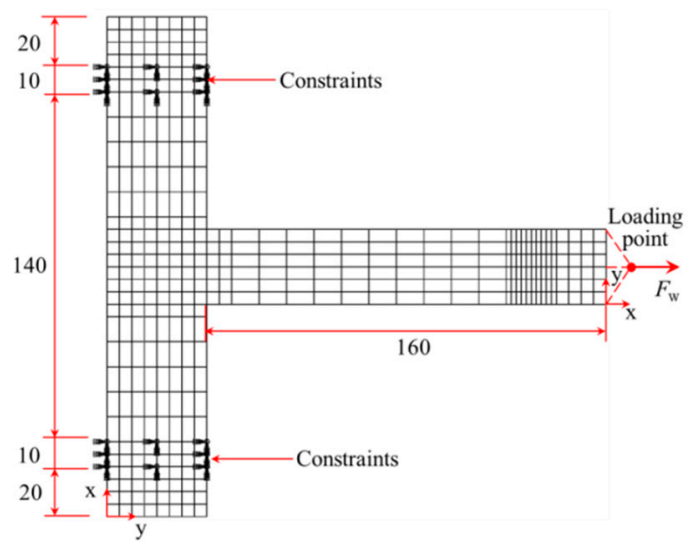

(a)

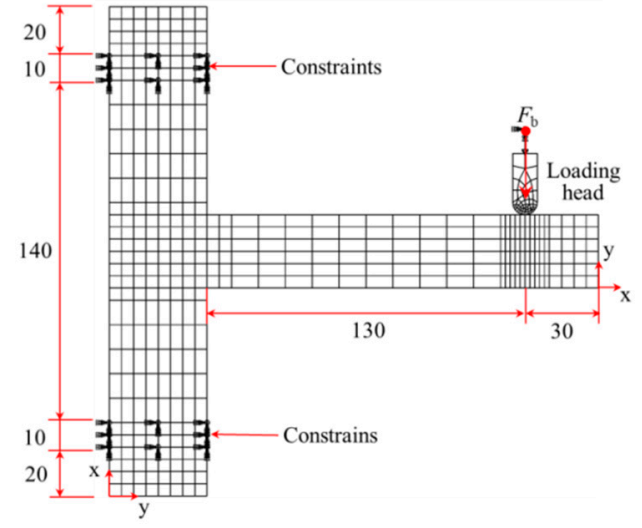

(b)

Figure 2. S Finite element models used to simulate (a) withdrawal load capacity and (b) bending load capacity.

\subsection{Experimental Design}

Firstly, experimental tests were designed to verify the effectiveness of the finite element model. The setup for testing withdrawal and bending load capacities are shown in Figure 3. A T-shaped mortise-and-tenon sample, with dimensions of $20 \mathrm{~mm} \times 25 \mathrm{~mm} \times 10 \mathrm{~mm}$ (length $\times$ width $\times$ thickness), was selected to verify the finite element model, with 10 replications for withdrawal and bending load tests.

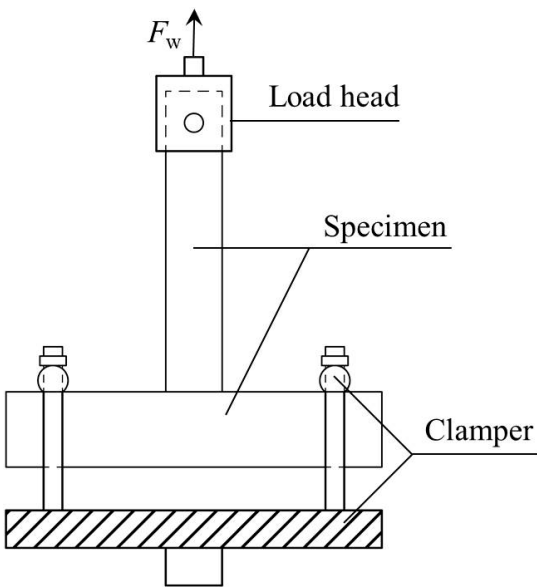

(a)

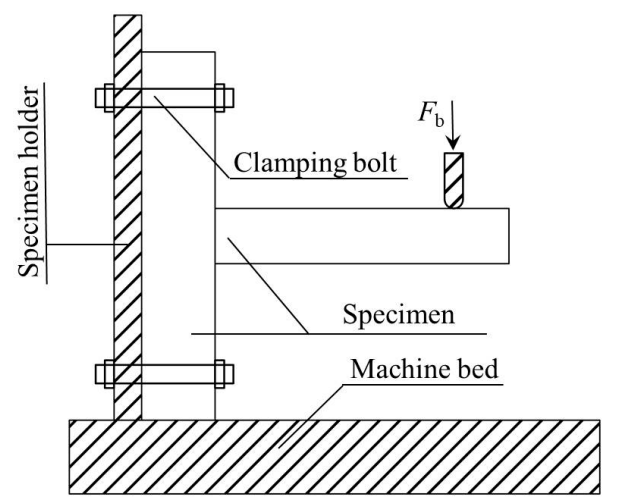

(b)

Figure 3. Setups for testing (a) withdrawal and (b) bending load capacities of M-T joints. 
Then, a complete $3 \times 3 \times 3$ factorial numerical test was implemented to investigate the effect of tenon sizes on withdrawal and bending load resistances. Therefore, twenty-seven T-shaped M-T joint finite element modes were established and analyzed to evaluate the influences of tenon geometry dimensions on the withdrawal and bending load resistances of M-T joints.

\subsection{Statistical Analysis}

The simulation results of withdrawal and bending load resistance were analyzed and optimized using the statistical software Design Expert (Version 8.06, Stat-Ease, Inc., Minneapolis, MN, USA) based on the RSM. The response surface models were built by the regression method, and the model terms were analyzed by analysis of variance (ANOVA), statistically. Model optimizations were also conducted by Design Expert.

\section{Results}

\subsection{Verification of Finite Element Model}

Figure 4 shows the withdrawal and bending load capacities of the experiments and FEA, which suggests that the ultimate withdrawal load and bending load of the experimental tests are similar to those of FEA. Although, in some, local parts of the curves are different, the general trends of the FEA curves are well consistent with those of the experimental tests, especially for the bending load-deflection curve. This is because the cohesive elements of the glue layer degraded fast, causing the load to decrease instantaneously, but the elements of the wood were not damaged; therefore, the bending load increased after instantaneous decrease. Table 2 shows the comparisons of the experimental tests with FEA regarding withdrawal and bending load capacities, indicating that the finite element established in this study is capable of optimizing the tenon geometric dimensions of M-T joint furniture.

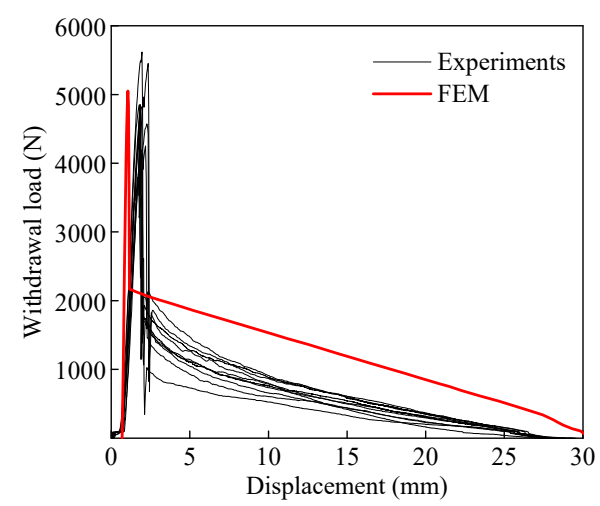

(a)

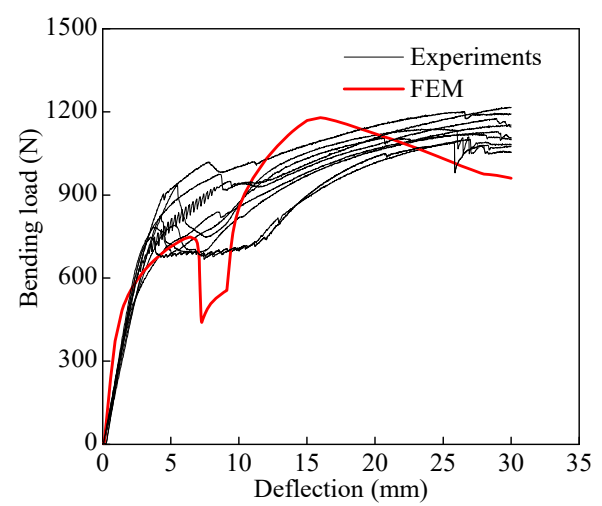

(b)

Figure 4. Comparisons of results between experiment and finite element analysis (FEA): (a) withdrawal and (b) bending load capacities.

Table 2. Comparison results of experiment and FEA.

\begin{tabular}{cccc}
\hline & FEA (N) & Experiment (N) & Ratio \\
\hline Withdrawal & 5813 & $5133(4.3)$ & 1.13 \\
Bending & 1163 & $1008(6.8)$ & 1.15 \\
\hline
\end{tabular}

\subsection{Withdrawal Load Capacities of FEA}

Figure 5 shows two typical failure modes of the finite element model when subjected to withdrawal load. Figure 5 a shows that the tenon detached from the mortise without obvious damage. Figure $5 \mathrm{~b}$ shows the tenon damage before being pulled out from the mortise. 


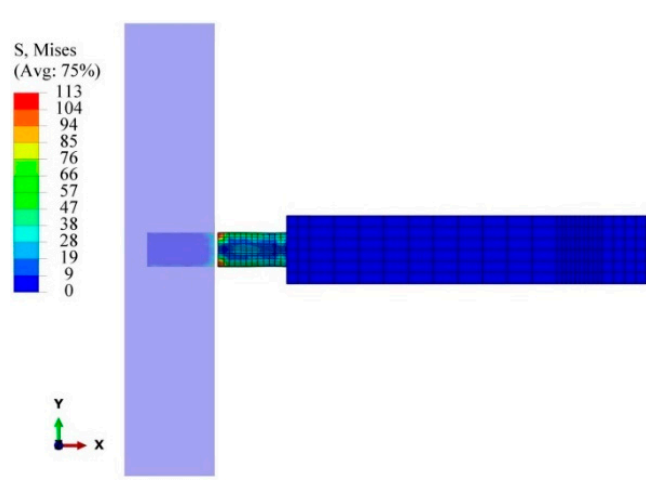

(a)

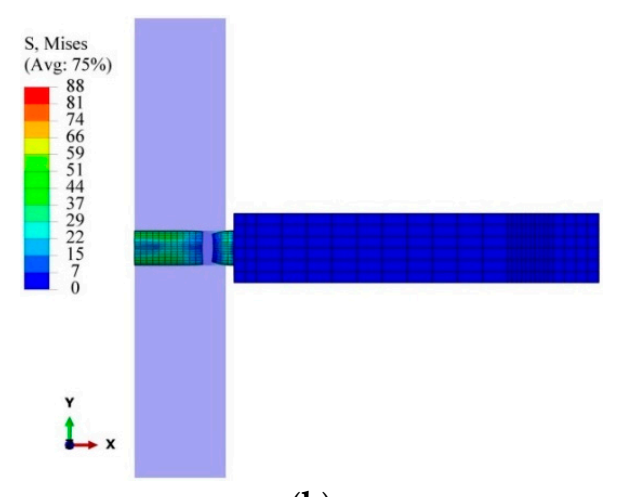

(b)

Figure 5. Typical failure modes of T-shaped specimens subjected to withdrawal load (a) when detached from tenon without damage, and (b) fracture of tenon.

Table 3 shows the values of withdrawal load resistances of all finite element models evaluated in this study.

Table 3. Comparisons of withdrawal load capacity for tenon thickness within each combination of tenon length and tenon width.

\begin{tabular}{|c|c|c|c|c|}
\hline \multirow{3}{*}{ Tenon Length (mm) } & \multirow{3}{*}{ Tenon Width (mm) } & \multicolumn{3}{|c|}{ Tenon Thickness (mm) } \\
\hline & & 7.5 & 10 & 15 \\
\hline & & \multicolumn{3}{|c|}{ (N) } \\
\hline \multirow{3}{*}{20} & 15 & 6047 & 6969 & 8779 \\
\hline & 20 & 5771 & 6359 & 8041 \\
\hline & 25 & 5483 & 5813 & 7252 \\
\hline \multirow{3}{*}{30} & 15 & $6045 *$ & 7433 & 10,324 \\
\hline & 20 & 7903 & 8280 & 11,192 \\
\hline & 25 & 7968 & 8427 & 10,372 \\
\hline \multirow{3}{*}{40} & 15 & $5738 *$ & $7457^{*}$ & 10,407 * \\
\hline & 20 & 8150 * & 9928 & 13,795 \\
\hline & 25 & 10,036 & 11,028 & 13,661 \\
\hline
\end{tabular}

* The values with an asterisk indicate that the failure of the joint was caused by the fracture of the tenon.

Table 4 lists the results of the statistical analysis used to select models to predict the withdrawal load capacity of M-T joints. The principles used to select the model were: (1) SD is the standard deviation of the error; the smaller the better; (2) $\mathrm{R}^{2}$ and related Adjusted $\mathrm{R}^{2}$ statistics should be close to 1 , which infers that the ideal case where 100 percent of the variation in the observed values can be explained by the chosen model; (3) the Predicted $\mathrm{R}^{2}$ evaluates the amount of variation in new data explained by the model. The closer to 1 , the better the predicted $\mathrm{R}^{2}$ is; (4) the value of predicted residual error sum of squares (PRESS) shows how well the model fits the data. The PRESS for the chosen model should be small, relative to the other models under consideration. Therefore, the quadratic model was chosen based on all of the above principles and is shown as Equation (1). The Predicted $\mathrm{R}^{2}$ of 0.9737 is well consistent with the Adjusted $\mathrm{R}^{2}$ of 0.9880 , which indicates that this model can be used to predict the withdrawal load capacities of the M-T joints evaluated in this study.

$F_{\mathrm{W}}=4386.5-228.5 l+344.8 w-265.4 t+15.51 w+15.2 l t-16.6 w t-0.84 l^{2}-14.3 w^{2}+25.7 t^{2}$

where $F_{\mathrm{W}}$ is withdrawal load capacity $(\mathrm{N}) ; l, w$, and $t$ are tenon length, tenon width, and tenon thickness $(\mathrm{mm})$, respectively. 
Table 4. Model summary statistics of withdrawal load resistance.

\begin{tabular}{cccccc}
\hline Model & SD & $\mathbf{R}^{\mathbf{2}}$ & Adjusted $\mathbf{R}^{\mathbf{2}}$ & Predicted R $^{\mathbf{2}}$ & PRESS $^{2}$ \\
\hline Linear & 605.80 & 0.9443 & 0.9350 & 0.9118 & $1.046 \times 10^{7}$ \\
2FI & 353.05 & 0.9842 & 0.9779 & 0.9670 & $3.908 \times 10^{6}$ \\
Quadratic & 259.85 & 0.9932 & 0.9880 & 0.9737 & $3.118 \times 10^{6}$ \\
Cubic & 271.13 & 0.9969 & 0.9870 & 0.9203 & $9.448 \times 10^{6}$ \\
\hline
\end{tabular}

Note: 2FI: two factors interaction linear model.

Table 5 shows the ANOVA of the model in terms of the response surface quadratic model. The F value of 193.78 indicates that the model is significant. Values of $\mathrm{p}$ less than 0.05 suggests that model terms are significant. In this case, $l, w, t, l w, l t, w t, w^{2}$, and $t^{2}$ are significant model terms. $p$ values greater than 0.1 suggest that the model terms are not significant. In this case, $l^{2}$ is not a significant term, suggesting that the effect of tenon width on withdrawal load capacity is not significant. In addition, the $F$ value of tenon length is bigger than tenon thickness and tenon width, which indicates that the tenon length has a greater effect than tenon thickness, followed by tenon width, on withdrawal load capacity.

Table 5. ANOVA of model terms in the response surface quadratic model of withdrawal load capacity.

\begin{tabular}{ccc}
\hline Source & F Value & $p$ Value \\
\hline Model & 193.78 & $<0.0001$ \\
$l$ & 419.50 & $<0.0001$ \\
$w$ & 7.07 & 0.0208 \\
$t$ & 386.85 & $<0.0001$ \\
$l w$ & 37.10 & $<0.0001$ \\
$l t$ & 35.05 & $<0.0001$ \\
$w t$ & 10.48 & 0.0071 \\
$l^{2}$ & 0.43 & 0.5222 \\
$w^{2}$ & 7.86 & 0.0159 \\
$t^{2}$ & 6.56 & 0.0249
\end{tabular}

The tenon geometry dimensions were optimized to get the maximum withdrawal load capacity. Equation (1) was set as the objective function. The constraints were that the tenon length was between $20 \mathrm{~mm}$ and $40 \mathrm{~mm}$, the tenon width was in the range of $15 \mathrm{~mm}$ to $25 \mathrm{~mm}$, and the tenon thickness changed from $7.5 \mathrm{~mm}$ to $15 \mathrm{~mm}$. The final goal was to get the maximum withdrawal load capacity. Based on the above conditions, Figure 6 shows the cubic space of the withdrawal load capacity relating to the tenon geometric dimensions (length, width, and thickness). The optimal solution was that the tenon length, tenon width, and tenon thickness were $39.97 \mathrm{~mm}, 24.77 \mathrm{~mm}$, and $14.99 \mathrm{~mm}$, respectively, with the maximum withdrawal load capacity of $13,799.8 \mathrm{~N}$, which was close to the simulation result.

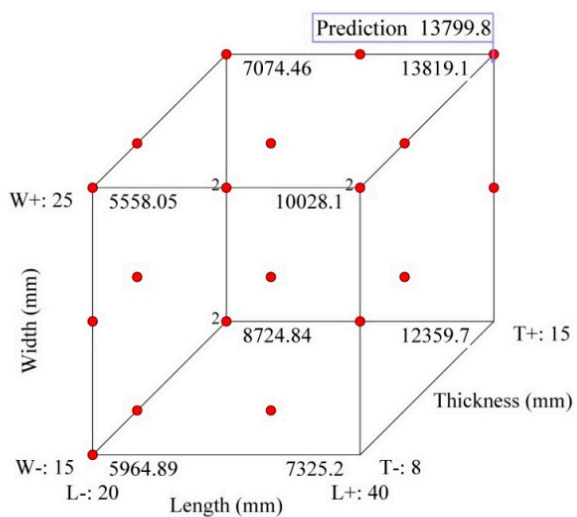

Figure 6. Cubic space of withdrawal load capacity relating to tenon length, tenon width, and tenon thickness. 


\subsection{Bending Load Capacity of FEA}

Figure 7 shows two typical failure modes of the $\mathrm{M}-\mathrm{T}$ joint finite element model when subjected to bending load. In the case of the failure mode shown in Figure 7a, the tenon was crushed at the front end. meanwhile, for Figure $7 \mathrm{~b}$, the tenon was fractured at the root. These two phenomena resulted from the ratio of tenon length to tenon width. When the ratio is smaller than 1, the M-T joint will be damaged, as in Figure 7a, otherwise the M-T joint will fracture as in Figure $7 \mathrm{~b}$.

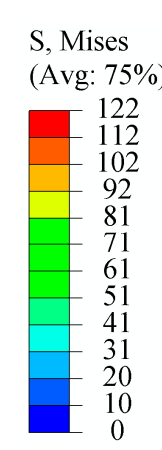

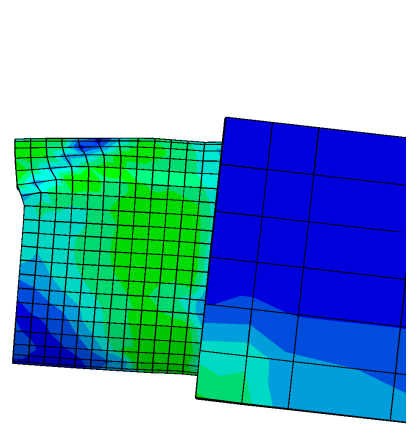

(a)

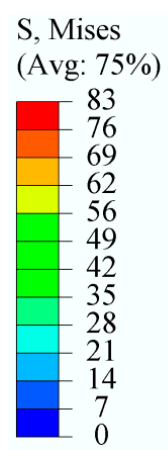

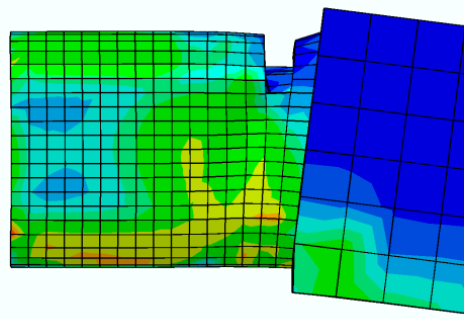

(b)

Figure 7. Typical failure modes of M-T joint finite element subjected to bending load (a) crushed at front end of the tenon and (b) damage at the root of the tenon.

Table 6 shows the bending load capacities of all tested finite element models with the different tenon geometric dimensions evaluated in this study.

Table 6. Comparisons of bending load capacities for tenon thickness within each combination of tenon length and tenon width.

\begin{tabular}{|c|c|c|c|c|}
\hline \multirow{3}{*}{ Tenon Length (mm) } & \multirow{3}{*}{ Tenon Width (mm) } & \multicolumn{3}{|c|}{ Tenon Thickness (mm) } \\
\hline & & 7.5 & 10 & 15 \\
\hline & & \multicolumn{3}{|c|}{ (N) } \\
\hline \multirow{3}{*}{20} & 15 & 615 & 748 & 935 \\
\hline & 20 & 771 & 921 & 1187 \\
\hline & 25 & 796 * & 1163 * & 1408 * \\
\hline \multirow{3}{*}{30} & 15 & 650 & 778 & 982 \\
\hline & 20 & 811 & 985 & 1276 \\
\hline & 25 & 990 & 1218 & 1546 \\
\hline \multirow{3}{*}{40} & 15 & 654 & 885 & 989 \\
\hline & 20 & 816 & 993 & 1283 \\
\hline & 25 & 1004 & 1222 & 1618 \\
\hline
\end{tabular}

* The values followed by an asterisk indicate that the failure of the joint was caused by the crushed tenon.

Table 7 lists the statistics used to compare models. The quadratic model (Equation (2)) was selected to predict the bending load capacity of the M-T joint relating to the tenon size based on the selection principles described previously. The Predicted $R^{2}$ of 0.9683 is well consistent with the Adjusted $R^{2}$ of 0.9822 , indicating that the model was capable of predicting the bending load resistance of the $\mathrm{M}-\mathrm{T}$ joints evaluated in this study.

$$
F_{\mathrm{b}}=143+10.5 l-18.8 w+72.9 t+0.4 l w+0.17 l t+3.5 w t-0.26 l^{2}+0.26 w^{2}-3.9 t^{2}
$$

where $F_{\mathrm{b}}$ is withdrawal load capacity $(\mathrm{N})$ and $l, w$, and $t$ are tenon length, tenon width, and tenon thickness $(\mathrm{mm})$, respectively. 
Table 7. Model summary statistics of bending load capacity.

\begin{tabular}{cccccc}
\hline Model & SD & $\mathbf{R}^{\mathbf{2}}$ & Adjusted $^{\mathbf{2}}$ & Predicted R $^{\mathbf{2}}$ & PRESS \\
\hline Linear & 65.21 & 0.9471 & 0.9402 & 0.9209 & $1.4641 \times 10^{5}$ \\
2FI & 44.28 & 0.9788 & 0.9724 & 0.9547 & $83,906.93$ \\
Quadratic & 35.61 & 0.9884 & 0.9822 & 0.9683 & $58,684.91$ \\
Cubic & 40.04 & 0.9913 & 0.9775 & 0.9070 & $1.722 \times 10^{5}$ \\
\hline
\end{tabular}

Table 8 shows the ANOVA of model terms in the response surface quadratic model. The $F$ value of 160.25 indicates that the model is significant. Values of $p$ less than 0.05 suggest that the model terms are significant. In this case, $l, w, t, w t$, and $t^{2}$ are significant model terms. Values of $p$ greater than 0.1 indicate that the model terms are not significant. In this case, $l w, l t$, and $w^{2}$ are not significant. In addition, the $F$ value of tenon thickness is much bigger than tenon width and tenon length, suggesting that the effect of tenon thickness on bending load capacity is greater than that of tenon width, followed by tenon length.

Table 8. Results of ANOVA of model terms in the response surface quadratic model.

\begin{tabular}{ccc}
\hline Source & $\boldsymbol{F}$ Value & $p$ Value \\
\hline Model & 160.25 & $<0.0001$ \\
$l$ & 37.47 & $<0.0001$ \\
$w$ & 641.20 & $<0.0001$ \\
$t$ & 742.65 & $<0.0001$ \\
$l w$ & 4.01 & 0.0615 \\
$l t$ & 0.41 & 0.5282 \\
$w t$ & 41.79 & $<0.0001$ \\
$l^{2}$ & 3.14 & 0.0941 \\
$w^{2}$ & 0.19 & 0.6658 \\
$t^{2}$ & 10.59 & 0.0047 \\
\hline
\end{tabular}

The tenon sizes were optimized to get the maximum bending load resistance using Design Expert software. Equation (2) was set as the objective function, and the constraints of the objective function were that the tenon length changed from $20 \mathrm{~mm}$ to $40 \mathrm{~mm}$, the tenon width was in the range of $15 \mathrm{~mm}$ to $25 \mathrm{~mm}$, and the tenon thickness was between $7.5 \mathrm{~mm}$ and $15 \mathrm{~mm}$. The final goal was to get the maximum withdrawal load capacity. After calculation, Figure 8 shows the cubic space of bending load capacity relating to tenon geometric dimensions. The optimal solution was that the tenon length, tenon width, and tenon thickness were $39.97 \mathrm{~mm}, 24.88$, and $15 \mathrm{~mm}$, respectively, with a maximum withdrawal load capacity of $1591.59 \mathrm{~N}$, which was well consistent with the simulation result.

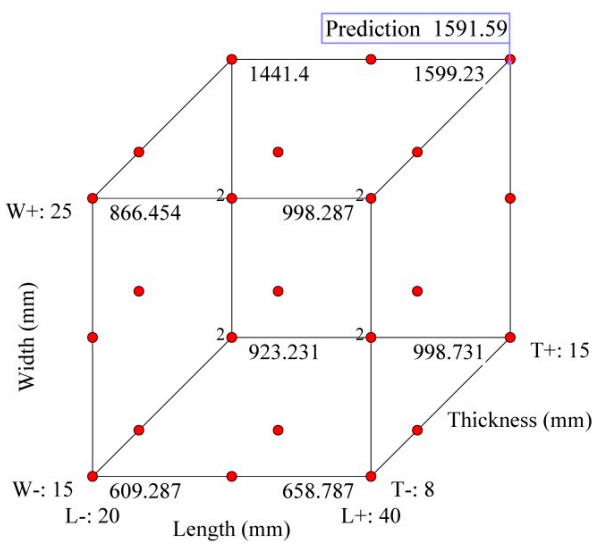

Figure 8. Cubic space of bending load capacity relating to tenon length, tenon width, and tenon thickness. 


\section{Discussion}

\subsection{Effect of Tenon Geometry Dimensions on Withdrawal Load Capacity}

The withdrawal load capacities increased remarkably with the increase of tenon length. The withdrawal load capacities also increased with the increase of tenon thickness compared within the same row. Comparing the withdrawal load capacities in the same column with the tenon length of $20 \mathrm{~mm}$, the withdrawal load capacities decreased slightly with the increase of tenon width. When the tenon length is $30 \mathrm{~mm}$, the withdrawal load capacities increased slightly with the increase of tenon width. In the case of a tenon length of $40 \mathrm{~mm}$, the withdrawal load capacities increased with the growth of tenon width, except for a tenon thickness of $15 \mathrm{~mm}$. In summary, it can be inferred that the longer the tenon is, the higher the withdrawal load capacity is, which is consistent with the results of $[3,4]$. However, when the tenon length is twice as big or equal to the tenon width, the material of the tenon will be damaged before being pulled out, which will reduce the withdrawal load capacity. Therefore, it is recommended that the tenon length is greater than the tenon width and smaller than twice the tenon width, especially, for M-T joints with a thin tenon thickness.

\subsection{Effect of Geometric Dimensions of Tenon on Bending Load Capacity}

The tenon geometry dimensions have significant effects on bending load capacity, and the bending load capacity increases with the increase of tenon sizes $[12,14,15]$. However, tenon thickness and tenon width have a greater effect on bending load resistances than tenon length with the dimensions evaluated in this study, which is in agreement with [16] but contrary to $[12,14,15]$. This may be because the loading types adopted in $[12,14,15]$ were diagonal compress or tension with L-shaped samples, but in this study, and in [16], the loading type was compress perpendicular to the stretcher of the T-shaped specimens. Therefore, further studies will focus on explaining this difference, and on studying other types of M-T joints with FEA.

\section{Conclusions}

In this study, the effects of tenon geometric dimensions, including tenon length, tenon width, and tenon thickness, on bending and withdrawal load capacity were studied through the use of FEA and RSM. The following conclusions were drawn:

(1) The tenon length has a greater effect on withdrawal load resistance than tenon thickness, followed by tenon width, while the effect of tenon thickness on bending load resistance is greater than that of tenon width, followed by tenon length.

(2) It is recommended that the tenon length is greater than the tenon width and smaller than twice the tenon width $(w<l<2 w)$, especially for relatively thin tenon thicknesses.

(3) Quadratic models relating to the tenon lengths, tenon widths, and tenon thicknesses proposed in this study was validated as an effective method to predict and optimize the withdrawal and bending load capacities of M-T joints.

(4) The maximum withdrawal and bending load resistances were obtained in this study when the tenon sizes were approximately $40 \mathrm{~mm}$ long $\times 25 \mathrm{~mm}$ wide $\times 15 \mathrm{~mm}$ thick.

In conclusion, the proposed method combining FEA with RSM is capable of being used to evaluate and design M-T joints, and to get more knowledge of $\mathrm{M}-\mathrm{T}$ joints visually. This study contributes to reducing the costs of both time and materials used in conducting experiments.

Author Contributions: Conceptualization, W.H.; methodology, W.H.; software, B.C.; validation, B.C.; formal analysis, W.H.; investigation, B.C.; resources, W.H.; data curation, B.C.; writing—original draft preparation, W.H. and B.C.; writing - review and editing, W.H.; supervision, W.H.; funding acquisition, W.H. Both authors have read and agreed to the published version of the manuscript. 
Funding: This work was supported by the Scientific Research Foundation of Metasequoia Teacher (163104060), and A Project from International Cooperation Joint Laboratory for Production, Education, Research, and Application of Ecological Health Care on Home Furnishing.

Institutional Review Board Statement: Not applicable.

Informed Consent Statement: Not applicable.

Data Availability Statement: The data presented in this study are available on request from the corresponding author. The data are not publicly available due to restriction of privacy.

Acknowledgments: The authors would like to thank Huiyuan Guan and Na Liu from the Department of Furniture Design of Nanjing Forestry University for their help in modelling. We also would like to thank the anonymous reviewers and editor for their valuable comments and suggestions for improving the quality of this paper.

Conflicts of Interest: The authors declare no conflict of interest.

\section{References}

1. Fu, W.; Guan, H.; Zhang, X. Verification and further study on method of measuring contact force between mortise and tenon joint. BioResources 2021, 16, 263-276. [CrossRef]

2. Gu, Y.; Zhang, J. Tensile properties of natural and synthetic rattan strips used as furniture woven materials. Forests 2020, 11, 1299. [CrossRef]

3. Eckelman, C.A.; Haviarova, E.; Tankut, A.; Denizli, N.; Akcay, H.; Erdil, Y. Withdrawal capacity of pinned and unpinned round mortise and tenon furniture joints. Forest Prod. J. 2004, 54, 185-191.

4. Derikvand, M.; Smardzewski, J.; Ebrahimi, G.; Dalvand, M.; Maleki, S. Withdrawal force capacity of mortise and loose tenon T-type furniture joints. Turk. J. Agric. For. 2013, 37, 377-384.

5. Wang, S.; Wu, Z.; Chen, L.; Yan, S.; Xu, L.; Guan, H. Effect of mortise and tenon size on compressive and tensile strength of a box connected by dovetail keys. BioResources 2020, 15, 5776-5786. [CrossRef]

6. Diler, H.; Acar, M.; Balıkçı, E.; Demirci, S.; Erdil, Y.Z. Withdrawal force resistance of T-type furniture joints constructed from various heat-treated wood species. BioResources 2017, 12, 7466-7478.

7. Zhou, C.; Huang, T.; Shuang, L. Image analysis system of intelligent smart home based on VR. IEEE Access 2020, 8, 14775-147764. [CrossRef]

8. Zhao, Z.; Sun, S.; Wu, D.; Zhang, M.; Huang, C.; Umemura, K.; Yong, Q. Synthesis and characterization of sucrose and ammonium dihydrogen phosphate (SADP) adhesive for plywood. Polymers 2019, 11, 1909. [CrossRef] [PubMed]

9. Liu, X.; Lv, M.; Liu, M.; Lv, J. Repeated humidity cycling's effect on physical properties of three kinds of wood-based panels. BioResources 2019, 14, 9444-9453. [CrossRef]

10. Barboutis, I.; Meliddides, T. Influence of the time between machining and assembly of mortise and tenon joints on tension strength of T-type joints. Ann. WULS-SGGW Wood Technol. 2011, 73, $23-29$.

11. Renbutsu, T.; Koizumi, A. Withdrawal properties of glued, round, mortise and tenon joints using greenwood shrinkage as a clamping pressure. Mokuzai Gakkaishi 2018, 64, 87-194. [CrossRef]

12. Wilczyński, A.; Warmbier, K. Effect of joint dimensions on strength and stiffness of tenon joints. Folia For. Pol. $2003,34,53-66$.

13. Likos, E.; Haviarova, E.; Eckelman, C.A.; Erdil, Y.Z.; Özcifci, A. Effect of tenon geometry, grain orientation, and shoulder on bending moment capacity and moment rotation characteristics of mortise and tenon joints. Wood Fiber Sci. 2012, 44, 462-469.

14. Oktaee, J.; Ebrahimi, G.; Layeghi, M.; Ghofrani, M.; Eckelman, C.A. Bending moment capacity of simple and haunched mortise and tenon furniture joints under tension and compression loads. Turk. J. Agric. For. 2014, 38, 291-297. [CrossRef]

15. Kasal, A.; Eckelman, C.A.; Haviarova, E.; Erdil, T.Z.; Yalcin, I. Bending moment capacities of L-shaped mortise and tenon joints under compression and tension loadings. BioResources 2015, 10, 7009-7020. [CrossRef]

16. Erdil, Y.Z.; Kasal, A.; Eckelman, C.A. Bending moment capacity of rectangular mortise and tenon furniture joints. Forest Prod. J. 2005, 55, 209-213.

17. Záborský, V.; Borůvka, V.; Kašičková, V.; Ruman, D. Effect of wood species, adhesive type and annual ring directions on the stiffness of rail to leg mortise and tenon furniture joints. BioResources 2017, 12, 7016-7031. [CrossRef]

18. Tankut, A.N.; Tankut, N.D. The effects of joint forms (shape) and dimensions on the strengths of mortise and tenon joints. Turk. J. Agric. For. 2005, 29, 493-498.

19. Wu, G.; Sun, J.; Huang, C.; Ren, H.; Zhao, R. Research progress on mechanical properties of tenon-mortise joints in traditional Chinese wood structures. J. Forest Eng. 2020, 5, 29-37. [CrossRef]

20. Chen, Y.; Yang, Y.; Zhang, Z. Study on small-diameter wood scrimber and furniture design. J. Forest Eng. 2019, 4, 155-159. [CrossRef]

21. Hu, W.G.; Wan, H.; Guan, H.Y. Size effect on the elastic mechanical properties of beech and its application in finite element analysis of wood structure. Forests 2019, 10, 783. [CrossRef] 
22. Xi, X.; Yang, Y.; Zhang, Z.F. Pull-out force and finite element analysis of T-type components of Vitex negundo L. scrimber with different node forms. J. Forest Eng. 2020, 5, 182-187. [CrossRef]

23. Smardzewski, J. Effect of wood species and glue type on contact stresses in a mortise and tenon joint. J. Mech. Eng. Sci. 2008, 222, 2293-2299. [CrossRef]

24. Prekrat, S.; Smardzewski, J. Effect of glueline shape on strength of mortise and tenon joint. Drv. Ind. 2010, 61, 223-228.

25. Çolakoglu, M.H.; Apay, A.C. Finite element analysis of wooden chair strength in free drop. Int. J. Phys. Sci. 2012, 7, 1105-1114. [CrossRef]

26. Chen, Y.; Zhu, J. Study on bending characteristics of fast growing eucalyptus bookcase shelves by using burgers model. Wood Res. 2019, 64, 137-144.

27. Kilic, K.; Kasal, A.; Kuskun, T.; Acar, M.; Edil, Y.Z. Effect of tenon size on static front to back loading performance of wooden chairs in comparison with acceptable design loads. BioResources 2018, 13, 256-271. [CrossRef]

28. Chen, Y.; Wu, Z. Study on structure optimization design of modified wood furniture tenon structure based on the finite element analysis of ANSYS. J. Intell. Fuzzy Syst. 2018, 34, 913-922. [CrossRef]

29. Hu, W.G.; Guan, H.Y. Study on elastic constants of beech in different stress states. J. Forest Eng. 2017, 2, 31-36. [CrossRef]

30. Hu, W.G.; Guan, H.Y. A finite element model of semi-rigid mortise-and-tenon joint considering glue line and friction coefficient. J. Wood Sci. 2019, 64, 14. [CrossRef]

31. Hu, W.G.; Guan, H.Y. Investigation on withdrawal force of mortise and tenon joint based on friction properties. J. Forest Eng. 2017, 2, 158-162. [CrossRef] 